\title{
Adherence to Blended or Face-to-Face Smoking Cessation Treatment and Predictors of Adherence: Randomized Controlled Trial
}

Lutz Siemer ${ }^{1,2}$, Dipl-Psych; Marjolein G J Brusse-Keizer ${ }^{3}$, PhD; Marloes G Postel ${ }^{4,5}$, PhD; Somaya Ben Allouch ${ }^{6}$, $\mathrm{PhD}$; Robbert Sanderman ${ }^{4,7}, \mathrm{PhD} ;$ Marcel E Pieterse ${ }^{2}, \mathrm{PhD}$

\footnotetext{
${ }^{1}$ Technology, Health \& Care Research Group, Saxion University of Applied Sciences, Enschede, Netherlands

${ }^{2}$ Centre for eHealth and Well-being Research, University of Twente, Enschede, Netherlands

${ }^{3}$ Medical School Twente, Medisch Spectrum Twente, Enschede, Netherlands

${ }^{4}$ Department of Psychology, Health \& Technology, University of Twente, Enschede, Netherlands

${ }^{5}$ Tactus Addiction Treatment, Enschede, Netherlands

${ }^{6}$ Digital Life Research Group, Amsterdam University of Applied Science, Amsterdam, Netherlands

${ }^{7}$ Department of Health Psychology, University Medical Center Groningen, Groningen, Netherlands
}

\section{Corresponding Author:}

Lutz Siemer, Dipl-Psych

Technology, Health \& Care Research Group

Saxion University of Applied Sciences

MH Tromplaan 28

Enschede, 7513 AB

Netherlands

Phone: 3117678025906

Email: 1.siemer@utwente.nl

\section{Abstract}

Background: Blended face-to-face and web-based treatment is a promising way to deliver smoking cessation treatment. Since adherence has been shown to be an indicator of treatment acceptability and a determinant for effectiveness, we explored and compared adherence and predictors of adherence to blended and face-to-face alone smoking cessation treatments with similar content and intensity.

Objective: The objectives of this study were (1) to compare adherence to a blended smoking cessation treatment with adherence to a face-to-face treatment; (2) to compare adherence within the blended treatment to its face-to-face mode and web mode; and (3) to determine baseline predictors of adherence to both treatments as well as (4) the predictors to both modes of the blended treatment.

Methods: We calculated the total duration of treatment exposure for patients $(\mathrm{N}=292)$ of a Dutch outpatient smoking cessation clinic who were randomly assigned either to the blended smoking cessation treatment $(n=130)$ or to a face-to-face treatment with identical components $(n=162)$. For both treatments (blended and face-to-face) and for the two modes of delivery within the blended treatment (face-to-face vs web mode), adherence levels (ie, treatment time) were compared and the predictors of adherence were identified within 33 demographic, smoking-related, and health-related patient characteristics.

Results: We found no significant difference in adherence between the blended and the face-to-face treatments. Participants in the blended treatment group spent an average of 246 minutes in treatment (median 106.7\% of intended treatment time, IQR $150 \%-355 \%$ ) and participants in the face-to-face group spent 238 minutes (median $103.3 \%$ of intended treatment time, IQR $150 \%-330 \%$ ). Within the blended group, adherence to the face-to-face mode was twice as high as that to the web mode. Participants in the blended group spent an average of 198 minutes (SD 120) in face-to-face mode (152\% of the intended treatment time) and 75 minutes (SD 53) in web mode (75\% of the intended treatment time). Higher age was the only characteristic consistently found to uniquely predict higher adherence in both the blended and face-to-face groups. For the face-to-face group, more social support for smoking cessation was also predictive of higher adherence. The variability in adherence explained by these predictors was rather low (blended $\mathrm{R}^{2}=0.049$; face-to-face $\mathrm{R}^{2}=0.076$ ). Within the blended group, living without children predicted higher adherence to the face-to-face mode $\left(\mathrm{R}^{2}=0.034\right)$, independent of age. Higher adherence to the web mode of the blended treatment 
was predicted by a combination of an extrinsic motivation to quit, a less negative attitude toward quitting, and less health complaints $\left(\mathrm{R}^{2}=0.164\right)$.

Conclusions: This study represents one of the first attempts to thoroughly compare adherence and predictors of adherence of a blended smoking cessation treatment to an equivalent face-to-face treatment. Interestingly, although the overall adherence to both treatments appeared to be high, adherence within the blended treatment was much higher for the face-to-face mode than for the web mode. This supports the idea that in blended treatment, one mode of delivery can compensate for the weaknesses of the other. Higher age was found to be a common predictor of adherence to the treatments. The low variance in adherence predicted by the characteristics examined in this study suggests that other variables such as provider-related health system factors and time-varying patient characteristics should be explored in future research.

Trial Registration: Netherlands Trial Register NTR5113; http://www.trialregister.nl/trialreg/admin/rctview.asp?TC=5113

(J Med Internet Res 2020;22(7):e17207) doi: 10.2196/17207

\section{KEYWORDS}

blended treatment; smoking cessation; adherence; predictors; tobacco; prevention

\section{Introduction}

\section{Background}

As smoking remains the leading cause of preventable death, cessation treatment is pivotal for public health promotion [1]. The introduction of electronic health (eHealth) [2] represents the expectation of information and communication technologies to improve health care [3]. However, adherence is generally low in web-based treatment [4] as well as in cessation treatment in general [5]. Low adherence is problematic because adherence has been shown to be an indicator of a treatment's acceptability and a determinant of treatment effectiveness [6-9]. Therefore, adherence should be optimized because-assuming a dose-response relationship [10]—patients are more likely to quit smoking if they are more exposed to active ingredients of the treatment [6]. Adherence in general can be defined as the extent to which a person's behavior (eg, taking medication, following a diet, or executing lifestyle changes) corresponds with recommendations from a health care provider [6]. In the context of behavioral change treatments such as smoking cessation, adherence issues are mainly related to premature termination of treatment and failure to perform tasks and exercises between sessions [11].

\section{Blended Treatment}

In the past few decades, a variety of effective interventions for smoking cessation have become available [12,13], including more recently developed eHealth services such as web-based interventions $[14,15]$ or mobile phone interventions $[16,17]$. At present, traditional face-to-face interventions on the one hand, and both web-based and mobile phone interventions on the other hand are increasingly being transferred to blended treatment. Blended treatment is a promising eHealth service, because it is expected that the strengths of one mode of delivery will compensate for the weaknesses of the other [4,18-23]. The main strength of face-to-face treatment is to provide personal attention of a professional, which could compensate for the lack of face-to-face contact in web-based treatment. In turn, a main feature of web-based care is the accessibility anytime and anywhere, which could compensate for the time between face-to-face sessions when the user needs support. Blended treatment is applied in diverse settings (eg, individual vs group setting [24]), addresses several health issues (eg, depression [25], anxiety [26], or addiction [10,22]), uses various tools (eg, web platforms, email, SMS text messaging, apps [20,27]), and uses different modes of delivery (eg, mainly web-based [28,29] vs mainly face-to-face $[26,30]$ or integrated $[10,22]$ vs sequential [29]). Since a clear definition of blended interventions is still missing [18], in this paper we define blended treatment as a combination of face-to-face sessions and web-based sessions to an integrated treatment that can be delivered by health care professionals on an outpatient basis. The blended intervention adopted in this study is an integrated equal blend of face-to-face treatment and treatment via an online platform.

\section{Adherence to Blended Treatment}

Blended treatment has been shown to positively influence adherence [4,31-33]. However, to the best of our knowledge, no studies to date have directly compared adherence to a blended treatment with adherence to either a web-based treatment or a face-to-face treatment with identical active components. In this study, we used data from the LiveSmokefree study [22], which is a randomized controlled trial (RCT) comparing the effectiveness of a blended face-to-face and web-based smoking cessation treatment to a comparable face-to-face treatment. In a prior study, we explored measurement methods and levels and predictors of adherence to the blended treatment by including the blended treatment group participants of the RCT only [10]. In the current study, we extended this previous work by including participants from the face-to-face treatment, allowing for a direct comparison of the levels of adherence between blended and face-to-face treatments. Furthermore, to explore whether both modes of delivery within the blended treatment were used in equal frequency, we also focused on levels of adherence within the blended group in the two modes.

\section{Predictors of Adherence}

When adherence is low, adherence predictors become an area of interest because they may provide insight into the cause of low adherence and can help to generate new approaches to improving treatment or better alignment between the patient and treatment. Adherence, in general, is determined by provider behaviors, health system factors, and patient characteristics, and the latter have been most extensively examined as predictors of adherence to traditional interventions [6]. Within the context 
of smoking cessation treatment-including both face-to-face and web-based treatments-several demographic, smoking-related, and health-related predictors of adherence have been examined. To date, several studies have indicated that the likelihood of being adherent may increase with a higher age [34,35], male gender [35], higher internet skills [36,37], negative attitude toward smoking and higher motivation to quit at baseline [38,39], higher self-efficacy at baseline [39], early success in quitting after the start of the treatment [7,34,40], and lower nicotine dependency at baseline with fewer withdrawal symptoms after quitting [35,38]. For blended treatment, our previous study showed that higher adherence was best predicted by marital status (ie, having a partner) and social modeling (ie, more nonsmoking friends/partner) [10]. Building on this work, we have expanded on these previous findings in the current study by examining the predictors for adherence to both treatment arms (blended and face-to-face) and additionally the two modes of delivery (face-to-face mode and web mode) in the blended arm.

\section{Objectives}

In detail, this study explored the following questions. With respect to adherence, we asked (1) how adherent are participants to blended compared to face-to-face treatment? and (2) within the blended treatment group, how adherent are the participants to the face-to-face mode compared to the web mode? With respect to predictors, we asked (1) which demographic, smoking-related, and health-related patient characteristics predict adherence to blended and to face-to-face treatments, and to both groups combined? and (2) within the blended group, which of these characteristics predict adherence to the face-to-face mode and to the web mode?

\section{Methods}

\section{Study Subjects}

In this study, we used the already available data from patients (blended $n=130$; face-to-face $n=162$ ) of a not yet completed nonblinded RCT on the effectiveness of a blended smoking cessation treatment compared with a face-to-face treatment (LiveSmokefree study, $\mathrm{n}=172$ allocated per group to determine a difference in abstinence rates of 5 percentage points with a power of $80 \%$ and $=.025$ ) [22]. The patients were referred to the outpatient smoking cessation clinic at Medical Spectrum Twente hospital (Enschede, the Netherlands) by the treating physicians of the hospital or by their general practitioners, and attended the initial treatment session between May 2015 and September 2018. Inclusion criteria were: (1) willing to quit smoking, (2) aged 18 or older, and (3) current daily smoker (at least one cigarette a day). Exclusion criteria were: (1) no internet access (ie, email, websites) and (2) not able to read or write in the Dutch language. In line with the Dutch Medical Research Ethics Committee guidelines, the study was approved by the accredited MEC Twente (P14-37/NL50944.044.14). Before initiation, the study was registered in the Netherlands Trial Registry (NTR5113). All patients had to sign an informed consent form before they were randomized.

\section{Randomization}

Patients were randomly assigned to either the blended or face-to-face group. Randomization was performed at the individual level (allocation ratio 1:1) using QMinim Online Minimization [41]. The minimization was stratified according to: (1) level of internet skills [42], (2) level of nicotine dependence (Fagerstrom) [43,44], and (3) the quitting strategy favored by the patient (stop at once, gradual change, scheduled reduced smoking; for details see the description of the study intervention below). The data used for QMinim minimization were collected using the baseline questionnaire completed online by the patient at home prior to the start of treatment.

\section{Study Interventions}

The study interventions to be compared were a blended face-to-face and web-based smoking cessation treatment and a face-to-face treatment alone. Except for the differences in mode of delivery (ie, face-to-face mode and web mode), both treatments included the following same features: (1) high-intensity treatments comprising 10 sessions with a total treatment time of 230 minutes (20 minutes each, except for the first that was 50 minutes); (2) delivered by health care professionals in an outpatient cessation clinic; (3) derived from the Dutch Guideline for Tobacco Addiction [45] fulfilling the requirements of the Dutch care module for smoking cessation [46]; (4) executed by counselors registered in the Dutch quality register of qualified smoking cessation counselors; (5) treatment costs reimbursed by the patient's health insurance; (6) supporting three quitting strategies that were chosen at the start of the treatment (stop at once, change gradually by increasing the number of daily activities that are performed smoke-free, or decrease smoking at regular intervals such as scheduled smoking reduction $100 \%-75 \%, 75 \%-50 \%$, etc). The chosen quitting strategy did not influence the course of the treatment in general. The order, pace, duration, and intensity were the same for all strategies.

Both the blended and face-to-face treatments included the following behavior change techniques, according to BCT taxonomy v1 of Michie et al [47]: 1.1 Goal setting (behavior), 1.2 Problem solving, 1.3 Goal setting (outcome), 1.4 Action planning, 1.5 Review behavior goal(s), 1.6 Discrepancy between current behavior and goal, 1.8 Behavioral contract, 1.9 Commitment, 2.3 Self-monitoring of behavior, 2.4 Self-monitoring of outcome(s) of behavior, 2.6 Biofeedback, 2.7 Feedback on outcome(s) of behavior, 3.1 Social support (unspecified), 4.2 Information about antecedents, 4.3 Reattribution, 5.1 Information about health consequences, 5.2 Salience of consequences, 5.3 Information about social and environmental consequences, 5.4 Monitoring of emotional consequences, 5.5 Anticipated regret, 5.6 Information about emotional consequences, 6.2 Social comparison, 6.3 Information about others' approval, 7.4 Remove access to the reward, 8.1 Behavioral practice/rehearsal, 8.2 Behavior substitution, 8.3 Habit formation, 8.4 Habit reversal, 8.6 Generalization of a target behavior, 8.7 Graded tasks, 9.1 Credible source, 9.2 Pros and cons, 9.3 Comparative imagining of future outcomes, 10.7 Self-incentive, 10.9 Self-reward, 11.1 Pharmacological support (eg, nicotine replacement therapy [patches, gum], bupropion, 
varenicline), 11.2 Reduce negative emotions, 12.1 Restructuring the physical environment, 12.2 Restructuring the social environment, 12.3 Avoidance/reducing exposure to cues for the behavior, 12.4 Distraction, 13.1 Identification of self as role model, 13.2 Framing/reframing, 13.5 Identity associated with changed behavior, 14.4 Reward approximation, 14.5 Rewarding completion, 14.6 Situation-specific reward, 14.7 Reward incompatible behavior, 14.8 Reward alternative behavior, 15.1 Verbal persuasion about capability, 15.3 Focus on past success, and 16.3 Vicarious consequences.

The face-to-face treatment consisted of 10 face-to-face sessions delivered at the outpatient smoking cessation clinic. The blended treatment comprised 5 face-to-face sessions at the outpatient clinic and 5 web-mode sessions delivered via an online treatment platform. Both the face-to-face and blended treatments consisted of both counselor-dependent and counselor-independent components. The counselor-dependent web-based components of the blended treatment were interactive and relied on (asynchronous) communication (email, messaging) between the counselor and participant. The counselor-independent components such as psychoeducational content or a smoking diary were used by the participants on their own and in their own time. In the face-to-face group, these components were provided in a paper manual that the participants took home. In the blended treatment, these components were accessible online. As such, both treatments were equivalent with regard to content and intensity. An additional benefit of the blended treatment was that the content of previous counselor-dependent components remained accessible as email and messaging correspondence saved online.

The most characteristic feature of the blended treatment examined in this study is an equal balance between the face-to-face and web mode sessions; that is, the focus of the treatment is neither on face-to-face mode nor web mode. In addition, there is constant alternation and interactive use of the two modes. Table 1 shows the order, timing, main features, duration, and modes of delivery of the treatment sessions in the face-to-face and blended treatments. Although an equal distribution was planned for the blended treatment with regard to the number of sessions, there was an uneven distribution for the duration of treatment because the first session (50 minutes for face-to-face mode) was longer than the remaining sessions (20 minutes for the face-to-face mode or 20 minutes for web mode); therefore, the participants in the blended group spent 130 minutes in face-to-face mode and 100 minutes in web mode.

A detailed description of the treatments can also be found in the protocol article of the RCT [22] and in the description of the user experience of the blended smoking cessation treatment [48]. Screenshots of the web sessions of the blended treatment are shown in Multimedia Appendix 1 to provide an impression of the look and feel of the web interventions.

Table 1. Order, timing, main features, duration, and mode of delivery of the treatment sessions in the face-to-face and blended groups according to treatment protocol.

\begin{tabular}{|c|c|c|c|c|c|}
\hline \multirow[t]{2}{*}{ Session } & \multirow[t]{2}{*}{ Week } & \multirow[t]{2}{*}{ Main features } & \multirow[t]{2}{*}{ Duration (minutes) } & \multicolumn{2}{|c|}{ Mode of delivery } \\
\hline & & & & $\mathrm{BSCT}^{\mathrm{a}}$ & $\mathrm{F} 2 \mathrm{~F}^{\mathrm{b}}$ \\
\hline 1 & 1 & Goal setting; prompt smoking diary; measure $\mathrm{CO}^{\mathrm{c}}$ & 50 & $\mathrm{~F} 2 \mathrm{~F}$ & $\mathrm{~F} 2 \mathrm{~F}$ \\
\hline 2 & 3 & Measures for self-control & 20 & Web & $\mathrm{F} 2 \mathrm{~F}$ \\
\hline 3 & 5 & Dealing with withdrawal & 20 & $\mathrm{~F} 2 \mathrm{~F}$ & $\mathrm{~F} 2 \mathrm{~F}$ \\
\hline 4 & 7 & Breaking habits & 20 & Web & $\mathrm{F} 2 \mathrm{~F}$ \\
\hline 5 & 9 & Dealing with triggers & 20 & $\mathrm{~F} 2 \mathrm{~F}$ & $\mathrm{~F} 2 \mathrm{~F}$ \\
\hline 6 & 11 & Food for thought & 20 & Web & $\mathrm{F} 2 \mathrm{~F}$ \\
\hline 7 & 14 & Think differently; measure $\mathrm{CO}$ & 20 & $\mathrm{~F} 2 \mathrm{~F}$ & $\mathrm{~F} 2 \mathrm{~F}$ \\
\hline 8 & 18 & Do differently & 20 & Web & $\mathrm{F} 2 \mathrm{~F}$ \\
\hline 9 & 22 & Action plan; measure $\mathrm{CO}$ & 20 & $\mathrm{~F} 2 \mathrm{~F}$ & $\mathrm{~F} 2 \mathrm{~F}$ \\
\hline 10 & 26 & Closure & 20 & Web & $\mathrm{F} 2 \mathrm{~F}$ \\
\hline
\end{tabular}

${ }^{\mathrm{a} B S C T}$ : blended smoking cessation treatment; total duration=230 minutes ( 130 minutes F2F mode, 100 minutes web mode).

${ }^{\mathrm{b}} \mathrm{F} 2 \mathrm{~F}$ : face-to-face treatment; total duration=230 minutes.

${ }^{\mathrm{c}} \mathrm{CO}$ : carbon monoxide.

\section{Data Collection}

\section{Patient Characteristics}

As part of the RCT (LiveSmokefree-study), 33 demographic, smoking-related, and health-related characteristics were assessed with the intake measurement using an online questionnaire. A detailed description of these characteristics is available in the protocol article of the RCT [22].

\section{Measuring Adherence}

Established measures for adherence to a blended treatment are still lacking. Therefore, for the 2018 study [10], we constructed a customized measure for adherence by selecting 18 patient activities (eg, using a web-based smoking diary tool, responding to counselors' messages) to trace adherence to the blended treatment. Adequacy of this adherence measure was confirmed by the observed dose-response relationship between adherence 
and the likelihood of quitting, which is consistent with the smoking cessation literature [6-9]. However, this activity-based method was quite detailed and labor-intensive and was particularly interesting from a methodological point of view. Since the current study was mainly focused on comparing treatment modalities in a clinical context, we used a simpler time-based method for measuring adherence, which was proven to be as suitable for clinical research as the activity-based method and was also found to be more efficient $[49,50]$. Although this time-based method was not as accurate as the activity-based method, it was applicable in this case because the primary goal of this study was to determine differences between the groups in terms of levels and predictors of adherence. Therefore, the analysis of relative level differences was more relevant than an exact measurement of absolute levels. Furthermore, the time-based method allowed for analysis of a larger sample and thus more accurate statistics, as it required less time and money.

For this time-based approach, we used treatment data from the hospital's electronic patient record system. This record system contains basic information of the patients' treatment status such as when the patient started treatment; which counselor was offering the treatment; time, day, and type of appointments; time and day of telephone consults; and which kind of treatment was offered in each appointment [51]. In this record system, the counselors reported, in an encoded form, which type of sessions were completed. Each code represents a fixed, average number of minutes invested in face-to-face mode or web mode, as shown in Table 2. These fixed numbers of minutes per sessions were used to calculate the total number of minutes in treatment for each patient for the blended and face-to-face treatments, as well as for the face-to-face mode and web mode in the blended treatment.

Table 2. Codes, descriptions, modes of delivery, and duration of face-to-face (F2F) and blended treatment sessions used to measure adherence.

\begin{tabular}{llll}
\hline Code & Description of the session & Mode & Duration (minutes) \\
\hline RSN & First individual F2F session at treatment start & F2F & 50 \\
RSAB & Like RSN, but visiting a patient at another department of the hospital & F2F & F2F \\
RSNS & Like RSN, but with 2 patients at the same time (eg, husband and wife) & F2F & 30 \\
RSC & Usual individual F2F session & F2F & 20 \\
RSAC & Additional consult (to add to RSN/RSAB/RSNS/RSC if more time is needed) & F2F & 20 \\
RSTC & Individual telephone consult & F2F & 20 \\
RSOC & Any other individual consult & Web & Web \\
RSIC & Web-mode treatment session via rokendebaas.nl & 20 \\
RSEC & Email consulting & & 10 \\
\hline
\end{tabular}

\section{Statistical Analysis}

All analyses were performed using SPSS version 24.

\section{Patient Characteristics}

For both the blended and face-to-face groups, 33 demographic, smoking-related, and health-related characteristics were measured and are reported as means (SDs) for normally distributed continuous variables and as medians (IQRs) for nonnormally distributed continuous variables. Categorical variables are reported as numbers with corresponding percentages. To identify between-group differences within the 33 demographic, smoking-related, and health-related patient characteristics, independent $t$ tests or Mann-Whitney $U$ tests were performed as appropriate for continuous variables; the Pearson Chi-square or Fisher exact test was performed for categorical variables.

\section{Adherence (Time Spent in Treatment)}

Based on the hospital administrational records, both the absolute treatment time (in minutes) and the proportional treatment time (in percentage) of the patients who had started treatment were calculated for the blended and face-to-face groups, as well as for the face-to-face mode and web mode of the blended treatment. Bar charts were used to compare how many patients spend how much time in the blended and face-to-face treatment on the one hand and in each mode of the blended treatment on the other hand. Mann Whitney $U$ tests were performed to compare the absolute treatment time of the blended and face-to-face treatments and the proportional treatment time for the face-to-face and web modes in the blended treatment.

\section{Predictors of Adherence}

To identify the predictors of adherence (as a continuous variable) within the 33 demographic, smoking-related, and health-related patient characteristics, Pearson or Spearman correlation tests were performed as appropriate for continuous variables; independent $t$ tests or Mann-Whitney $U$ tests were performed for dichotomous variables. Variables with significance at $P<.15$ were considered as candidates for multivariate linear regression analyses. They were first tested with univariate linear regression analyses so that univariate and multivariate odds ratios could be compared, and were entered in the multivariate linear regression analyses after checking for multicollinearity. The variables were either all entered and removed step by step via the backward selection method (all patients; blended group; face-to-face group; face-to-face mode of the blended treatment) or entered step by step via the forward selection method (web mode of the blended treatment). Variables were entered or eliminated step by step based on the model fit. In the case of 
multicollinearity, the variable with the best model fit was selected for linear analyses.

\section{Results}

\section{Participant Flow}

Figure 1 shows the flow of participants through the study. A total of 292 patients were eligible for the study, provided written consent, filled out the baseline questionnaire, and were randomized (blended $n=130$; face-to-face $n=162$ ). Before the start of treatment, $7 / 130(5.4 \%)$ patients of the blended group and $6 / 162(3.7 \%)$ patients of the face-to-face group withdrew. Finally, data from 123/130 (94.6\%) patients in the blended group and 156/160 (96.3\%) patients in the face-to-face group were available for adherence analysis.

Figure 1. Flow of participants through the study. BSCT: blended smoking cessation treatment; F2F: face-to-face.

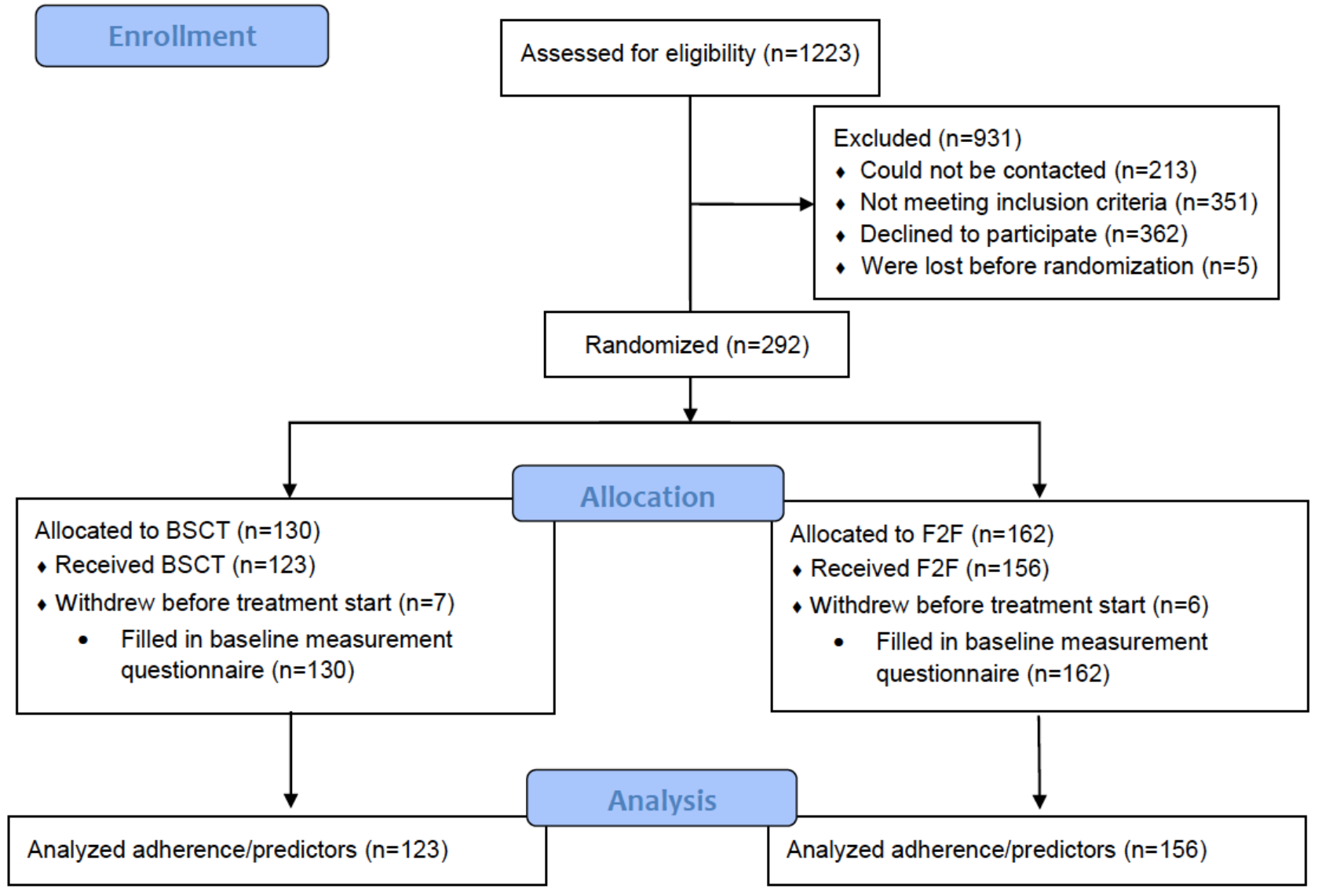

\section{Patient Characteristics}

Table 3 shows the patients' characteristics for both the blended group $(n=130)$ and the face-to-face group $(n=162)$. Significant differences $(P<.05)$ between the blended and face-to-face group were found for 6 of the 33 characteristics. Patients in the face-to-face group had higher internet skills, used more medication in general, reported less health complaints, and scored higher on the Depression Anxiety Stress Scale (DASS) subscales depression and anxiety, and on the total DASS score. 
Table 3. Patients' characteristics of both the blended smoking cessation treatment (BSCT) and face-to-face (F2F) groups.

\begin{tabular}{|c|c|c|c|}
\hline Characteristic & $\begin{array}{l}\text { BSCT } \\
(n=130)\end{array}$ & $\begin{array}{l}\text { F2F } \\
(n=162)\end{array}$ & $P$ value \\
\hline \multicolumn{4}{|l|}{ Demographic characteristics } \\
\hline Sex (female), n (\%) & $62(47.7)$ & $77(47.5)$ & .98 \\
\hline Age (years), mean (SD) & $47.1(12.8)$ & $46.6(13.2)$ & .76 \\
\hline Marital status, n (\%) & & & .18 \\
\hline With partner & $87(66.9)$ & $96(59.3)$ & \\
\hline Single & $43(33.1)$ & $66(40.7)$ & \\
\hline Housing situation, n (\%) & & & .91 \\
\hline Children & $54(41.5)$ & $65(40.9)$ & \\
\hline No children & $76(58.5)$ & $94(59.1)$ & \\
\hline Education, n (\%) & & & .88 \\
\hline $\mathrm{VET}^{\mathrm{a}}$ or higher & $82(63.1)$ & $101(63.9)$ & \\
\hline Lower than VET & $48(36.9)$ & $57(36.5)$ & \\
\hline Main income, $\mathbf{n}(\%)$ & & & .73 \\
\hline Wage or own company & $64(48.2)$ & $83(51.2)$ & \\
\hline Income support & $66(50.8)$ & $79(48.8)$ & \\
\hline Main day activity, n (\%) & & & .72 \\
\hline Paid work & $61(46.9)$ & $79(49.1)$ & \\
\hline Other & $69(53.1)$ & $82(50.9)$ & \\
\hline Internet skills ${ }^{\mathrm{b}}$, mean (SD) & $38.5(5.64)$ & $40.52(8.63)$ & .01 \\
\hline \multicolumn{4}{|l|}{ Smoking-related characteristics } \\
\hline Reason to start treatment, n (\%) & & & .70 \\
\hline Intrinsic & $83(63.8)$ & $107(66.0)$ & \\
\hline Extrinsic & $47(36.2)$ & $55(34.0)$ & \\
\hline Nicotine dependency ${ }^{\mathrm{c}}$, mean (SD) & $5.29(2.10)$ & $5.00(2.18)$ & .59 \\
\hline Negative attitude toward quitting ${ }^{\mathrm{d}}$, mean (SD) & $-5.70(3.16)$ & $-5.00(2.96)$ & .07 \\
\hline Positive attitude toward quitting ${ }^{\mathrm{e}}$, median $\left(\mathrm{IQR}^{\mathrm{c}}\right)$ & $10(8-12)$ & $10(8.75-11)$ & .91 \\
\hline Self-efficacy ${ }^{\mathrm{f}}$, mean (SD) & $-0.37(5.32)$ & $-0.45(5.02)$ & .89 \\
\hline Readiness to quit ${ }^{\mathrm{g}}$, median (IQR) & $2(1-3)$ & $2(1-3)$ & .31 \\
\hline Earlier quit attempts, n (\%) & $108(83.1)$ & $143(88.3)$ & .20 \\
\hline Social support ${ }^{\mathrm{h}}$, median (IQR) & $4(3-5)$ & $4(3-5)$ & .99 \\
\hline Social modeling ${ }^{\mathrm{i}}$, median (IQR) & $3.5(1-6)$ & $3(1-5)$ & .13 \\
\hline Use of alcohol ${ }^{\mathrm{j}}, \mathrm{n}(\%)$ & $2(1-3)$ & $2(0.75-3)$ & .26 \\
\hline Use of (recreational) drugs, $\mathrm{n}(\%)$ & $11(8.5)$ & $14(8.7)$ & .94 \\
\hline \multicolumn{4}{|l|}{ Health-related characteristics } \\
\hline Use of medication in general, $\mathrm{n}(\%)$ & $85(65.4)$ & $123(75.9)$ & .05 \\
\hline Use of medication for addiction treatment, $\mathrm{n}(\%)$ & $0(0.0)$ & $0(0.0)$ & $\mathrm{N} / \mathrm{A}^{\mathrm{k}}$ \\
\hline Use of medication for psychiatric treatment, n (\%) & $26(20.0)$ & $23(15.1)$ & .28 \\
\hline Use of medication for physical treatment, $\mathrm{n}(\%)$ & $64(49.2)$ & $88(57.9)$ & .15 \\
\hline Use of other medication, $\mathrm{n}(\%)$ & 19 (14.6) & $31(20.4)$ & .21 \\
\hline
\end{tabular}




\begin{tabular}{|c|c|c|c|}
\hline Characteristic & $\begin{array}{l}\text { BSCT } \\
(n=130)\end{array}$ & $\begin{array}{l}\text { F2F } \\
(n=162)\end{array}$ & $P$ value \\
\hline Health complaints (MAPHSS ${ }^{1}$ ), mean (SD) & $12.58(6.27)$ & $10.96(7.17)$ & .04 \\
\hline Smoking-related complaints ${ }^{\mathrm{m}}$, mean (SD) & $20.82(9.17)$ & $19.95(8.86)$ & .41 \\
\hline Health and smoking-related complaints ${ }^{\mathrm{n}}$, mean (SD) & $33.56(13.87)$ & $30.91(14.42)$ & .11 \\
\hline Depression $^{\mathrm{O}}$, median (IQR) & $4(0-10)$ & $4(2-24)$ & .02 \\
\hline Anxiety $^{\mathrm{o}}$, median (IQR) & $4(2-8)$ & $6(2-16.5)$ & .002 \\
\hline Stress $^{\mathrm{o}}$, median (IQR) & $8(4-16)$ & $10(4-14)$ & .73 \\
\hline $\mathrm{DASS}^{\mathrm{p}}$, median (IQR) & $18(8-32)$ & $22(8-58.5)$ & .01 \\
\hline EQ-5D-3L ${ }^{\mathrm{q}}$, median (IQR) & $0.77(0.69-1.00)$ & $0.77(0.69-1.00)$ & .42 \\
\hline EQ VAS ${ }^{\mathrm{r}}$, mean $(\mathrm{SD})$ & $66.95(16.88)$ & $65.17(17.56)$ & .38 \\
\hline
\end{tabular}

${ }^{\mathrm{a}}$ VET: vocational education and training.

${ }^{\mathrm{b}}$ Scored on a scale of 10-60; a higher score indicates better skills.

${ }^{\mathrm{c}}$ Fagerstroem scale (range 0-10); a higher score indicates higher nicotine dependency.

${ }^{\mathrm{d}}$ Scored on a scale of -12 to 0 ; a lower score indicates a more negative attitude.

${ }^{\mathrm{e}} \mathrm{S}$ cored on a scale of -12 to 0 ; a higher score indicates a more positive attitude.

${ }^{\mathrm{f}} \mathrm{Scored}$ on a scale of -12 to 12 ; a higher score indicates higher self-efficacy.

${ }^{\mathrm{g}} \mathrm{Scored}$ on a scale of 0-4; a higher score indicates greater readiness to quit.

${ }^{\mathrm{h}}$ Scored on a scale of 0-5; a higher score indicates more social support.

${ }^{\mathrm{i}} \mathrm{S}$ cored on a scale of 0-8; a higher score indicates more smokers in the social environment.

${ }^{\mathrm{j}}$ Scored on a scale of 0-4; a higher score indicates higher alcohol consumption.

${ }^{\mathrm{k}} \mathrm{N} / \mathrm{A}$ : not applicable; no statistical analysis performed since the variable is constant.

${ }^{1}$ MAPHSS: Maudsley Addiction Profile Health Symptoms Scale (range 0-40; a higher score indicates poorer health status).

${ }^{\mathrm{m}}$ Scored on a scale of 0-64; a higher score indicates more smoking-related complaints.

${ }^{\mathrm{n}} \mathrm{Scored}$ on a scale of 0-104; a higher score indicates poorer health status and more smoking-related complaints.

${ }^{\circ}$ Scored on a scale of 0-42; a higher score indicates a higher level of depression/anxiety/stress.

PDASS: Depression Anxiety Stress Scale; sum of the Depression, Anxiety, and Stress subscale scores (range 0-126; a higher score indicates a more negative emotional status).

${ }^{\mathrm{q}}$ EQ-5D-3L: societal-based quantification of health status (range 0-1; a higher score indicates better health status).

${ }^{r}$ EQ VAS: visual analog scale for quality of life (range 0-100; a higher score indicates better health status).

\section{Adherence (Time Spent in Treatment)}

As illustrated in Figure 2, adherence to the blended and face-to-face treatments was comparable. Patients in the blended group $(n=123,7$ patients dropped out between inclusion and the first treatment session) spent a median of 246 (IQR 150-355) minutes in treatment $(106.7 \%$ of the intended total treatment time); in the face-to-face group ( $n=156,6$ patients dropped out between inclusion and first treatment session), the patients spent a median of 238 (IQR 150-330) minutes in treatment (103.3\% of the intended total treatment time). There was no significant difference between the two groups $(P=.30)$. However, within the blended group, as shown in Figure 3, patients were more adherent to the face-to-face mode than to the web mode. Patients in the blended group $(n=123)$ spent a mean of 198 (SD 120) minutes in face-to-face mode and 75 (SD 53) minutes in web mode. In proportion to the intended treatment time for each mode of delivery (face-to-face mode $=130$ minutes; web mode $=100$ minutes), patients in the blended group spent twice the time in face-to-face mode (mean $152 \%$, SD $92 \%$ of 130 minutes) than in web mode (mean $75 \%$, SD $53 \%$ of 100 minutes $)\left(t_{122}=10.03 ; P<.001\right)$. 
Figure 2. Adherence to blended smoking cessation treatment (BSCT) vs face-to-face (F2F) treatment.

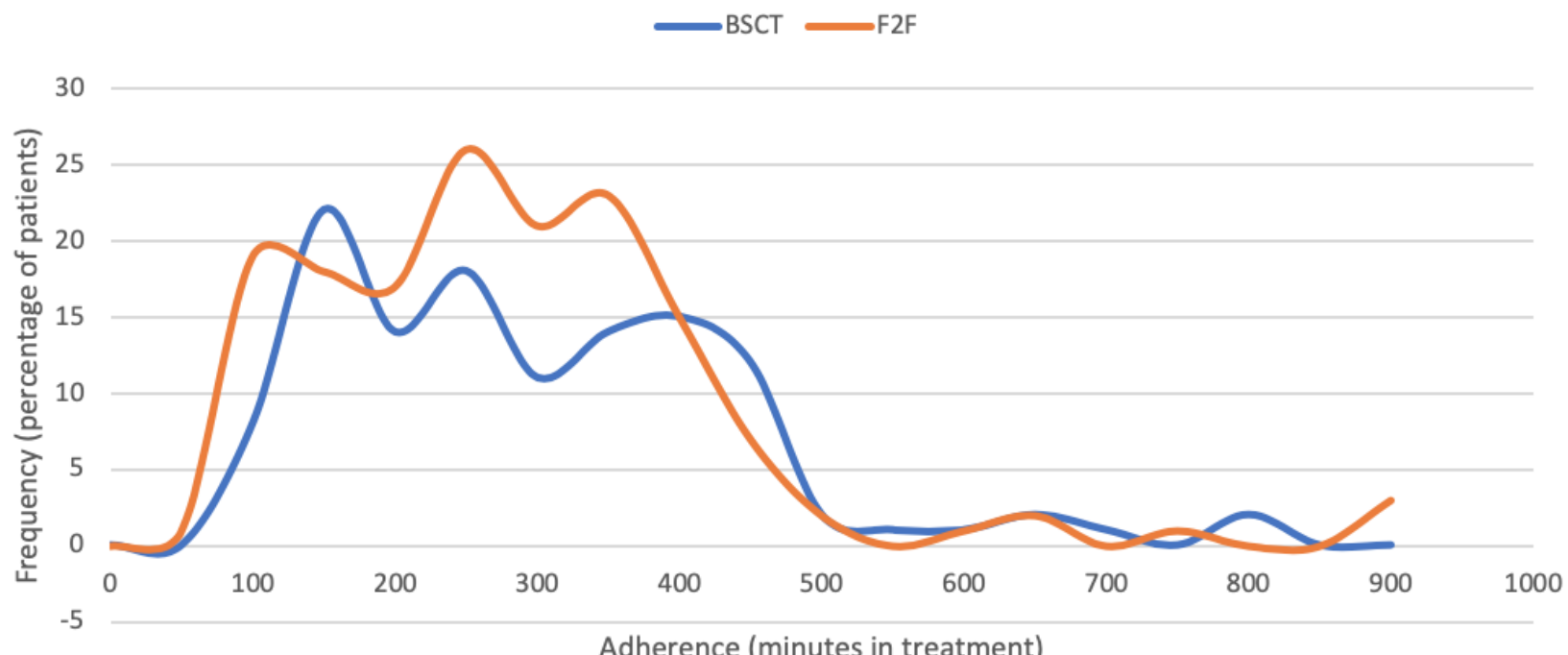

Figure 3. Adherence within the blended smoking cessation treatment group to the two modes of the treatment: face-to-face (F2F) mode vs web mode.

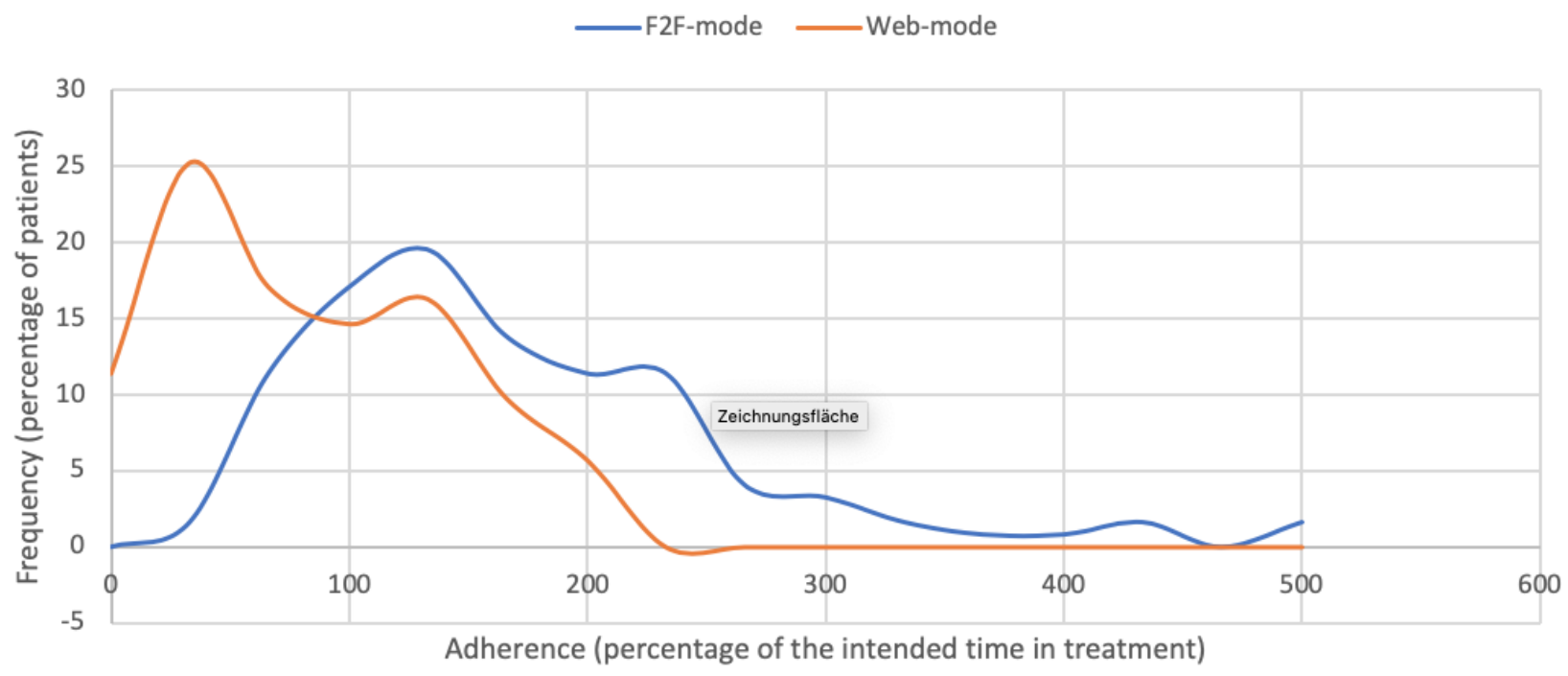

\section{Predictors of Adherence}

For both treatments together, 7 predictors (Table 4) were significantly associated with higher adherence in the univariate analysis (assessed at $P<.15$ ), including male sex, older age, housing situation (living without children), higher readiness to quit, higher social support, lower social modeling (less smokers in the social environment), and higher use of other medication. Multivariate regression analyses (Table 5) revealed that age was the best predictor of adherence $\left(\mathrm{R}^{2}=0.047\right)$. Per life year, patients spent 2.5 more minutes in treatment (95\% CI 1.2-3.8; $P=.001)$.

For the face-to-face group, 6 predictors (Table 4) were significantly associated with higher adherence in the univariate analyses (assessed at $P<.15$ ), including older age, higher readiness to quit, more social support, lower social modeling, higher use of other medication, and higher smoking-related complaints. Multivariate regression analyses (Table 5) revealed that age and social support together were the best predictors of adherence $\left(\mathrm{R}^{2}=0.076\right)$. Per life year, patients spent 2.2 minutes more in treatment (95\% CI 0.4-3.9; $P=.02)$. For social support, graded from 0 (low social smoking cessation support) to 5 (high social smoking cessation support), each unit increase was associated with 20.5 more minutes in treatment $(95 \%$ CI 2.3-38.8; $P=.03)$.

For the blended group, 8 predictors (Table 4) were significantly associated with higher adherence in the univariate analyses (assessed at $P<.15$ ), including higher age, housing situation (living without children), lower nicotine dependency (Fagerstroem), higher negative attitude toward quitting, lower social modeling, lower health complaints, lower anxiety, and lower stress. Multivariate regression analyses (Table 5) revealed that age was the best predictor of adherence $(P=.01)$. Per life year, patients spent 2.6 more minutes in treatment $(95 \% \mathrm{CI}$ $0.5-4.6 ; \mathrm{R}^{2}=0.049$ ).

For the face-to-face mode of the blended treatment, 3 predictors (Table 6) were significantly associated with higher adherence in univariate analyses (assessed at $P<.15$ ), including higher age, 
housing situation (living without children), and lower internet skills (Table 6). Multivariate regression analyses (Table 7) revealed that housing situation was the best predictor of face-to-face mode adherence $\left(\mathrm{R}^{2}=0.034\right)$. Patients living without children spent 49.7 more minutes in the face-to-face mode of the blended treatment (95\% CI 92.7-6.8; $P=.02$ ) (Table 7).

For the web mode of the blended treatment, 16 predictors (Table $6)$ were significantly associated with higher adherence in univariate analyses (assessed at $P<.15$ ), including male sex, older age, main income (income support), main day activity (other than paid work), extrinsic reason to start treatment, lower nicotine dependency (Fagerstroem), higher negative attitude toward quitting, higher self-efficacy, lower social modeling, lower health complaints (assessed on the Maudsley Addiction Profile Health Symptoms Scale [MAPHSS]), lower smoking-related complaints, lower health and smoking-related complaints, lower anxiety, lower stress, lower DASS, and higher quality of life (EQ-5D-3L). Health and smoking-related complaints and the DASS were not used for multivariate regression because of multicollinearity. Multivariate regression analyses (Table 7) revealed that reason to start treatment, negative attitude toward quitting, and health complaints (MAPHSS) together were the best predictors of web mode adherence $\left(\mathrm{R}^{2}=0.164\right)$. Patients with an intrinsic motivation spent 21.5 less minutes in the web mode of the blended treatment $(95 \% \mathrm{CI}-39.8$ to $-3.3 ; P=.02)$. For negative attitude toward quitting (range -12 to 0 ; lower numbers indicate a more negative attitude toward quitting smoking), each unit increase (ie, a less negative attitude) was associated with 3.6 more minutes in web mode of the blended treatment (95\% CI 0.9-6.4, $P=.01$ ). For health complaints (range 0-40; higher numbers indicate poorer health status), each unit increase (ie, additional complaint reported) was associated with 2.4 less minutes in the web mode of the blended treatment $(95 \%$ CI -3.8 to -1.0 , $P=.001)$.

Table 4. Univariate predictors for adherence in all patients and in each treatment group.

\begin{tabular}{|c|c|c|c|c|c|c|}
\hline \multirow[t]{2}{*}{ Characteristic } & \multicolumn{2}{|l|}{ All patients } & \multicolumn{2}{|l|}{$\mathrm{F} 2 \mathrm{~F}^{\mathrm{a}}$} & \multicolumn{2}{|l|}{$\mathrm{BSCT}^{\mathrm{b}}$} \\
\hline & $\begin{array}{l}\text { Regression coeffi- } \\
\text { cient }(95 \% \mathrm{CI})\end{array}$ & $P$ value & $\begin{array}{l}\text { Regression coefficient } \\
(95 \% \mathrm{CI})\end{array}$ & $P$ value & $\begin{array}{l}\text { Regression coefficient } \\
(95 \% \mathrm{CI})\end{array}$ & $P$ value \\
\hline Sex & & .11 & & $-^{c}$ & & - \\
\hline Female (reference) & $\mathrm{N} / \mathrm{A}^{\mathrm{d}}$ & & - & & - & \\
\hline Male & $28.6(-6.4-63.6)$ & & - & & - & \\
\hline Age (years) & $2.5(1.2-3.8)$ & .001 & $2.4(0.7-4.2)$ & .01 & $2.6(0.5-4.6)$ & .01 \\
\hline Housing situation & & .13 & & - & & .05 \\
\hline Children (reference) & N/A & & - & & - & \\
\hline No children & $27.8(-8.0-63.6)$ & & - & & $52.9(105.6-0.4)$ & \\
\hline Nicotine dependency & - & - & - & - & $-10.9(-23.3-1.4)$ & .08 \\
\hline Negative attitude toward quitting & - & - & - & - & $6.6(-1.6-14.7)$ & .11 \\
\hline Readiness to quit & $16.0(-1.5-33.6)$ & .07 & $21.1(-3.3-45.5)$ & .09 & - & - \\
\hline Social support & $13.6(0.5-26.8)$ & .04 & $23.3(4.5-41.7)$ & .01 & - & - \\
\hline Social modeling & $-8.4(-15.5$ to -1.5$)$ & .02 & $-10.1(-20.0$ to -0.1$)$ & .05 & $-7.5(-17.1-2.2)$ & .13 \\
\hline Use of other medication & & .06 & & .06 & & - \\
\hline Yes (reference) & N/A & & N/A & & - & \\
\hline No & $-36.8(-75.0-1.3)$ & & $-53.2(-108.1-1.7)$ & & - & \\
\hline Health complaints $\left(\right.$ MAPHSS $^{\mathrm{e}}$ ) & - & & - & & $-3.4(-7.5-0.7)$ & .10 \\
\hline Smoking-related complaints & - & & $2.20(-0.5-4.9)$ & .10 & - & \\
\hline Anxiety & - & & - & & $-3.5(-8.0-0.9)$ & .12 \\
\hline Stress & - & & - & & $-2.8(-6.2-0.6)$ & .11 \\
\hline
\end{tabular}

${ }^{\mathrm{a}} \mathrm{F} 2 \mathrm{~F}$ : face-to-face treatment group.

${ }^{\mathrm{b}} \mathrm{BSCT}$ : blended smoking cessation treatment group.

${ }^{\mathrm{c}}$ Data not shown, since for the sake of clarity only variables included in the multivariate regression at $P<.15$ are shown in the table.

${ }^{\mathrm{d}} \mathrm{N} / \mathrm{A}$ : not applicable.

e MAPHSS: Maudsley Addiction Profile Health Symptoms Scale. 
Table 5. Multivariate model of patient characteristics predicting adherence for all patients and each treatment group.

\begin{tabular}{|c|c|c|c|c|c|c|}
\hline \multirow[t]{2}{*}{ Variable } & \multicolumn{2}{|l|}{ All patients } & \multicolumn{2}{|l|}{$\mathrm{F} 2 \mathrm{~F}^{\mathrm{a}}$} & \multicolumn{2}{|l|}{$\mathrm{BSCT}^{\mathrm{b}}$} \\
\hline & $\begin{array}{l}\text { Regression coefficient } \\
(95 \% \mathrm{CI})\end{array}$ & $P$ value & $\begin{array}{l}\text { Regression coefficient } \\
(95 \% \mathrm{CI})\end{array}$ & $P$ value & $\begin{array}{l}\text { Regression coefficient } \\
(95 \% \mathrm{CI})\end{array}$ & $P$ value \\
\hline Age (years) & $2.5(1.2-3.8)$ & .001 & $2.2(0.4-3.9)$ & .02 & $2.6(0.5-4.6)$ & .01 \\
\hline Social support & $\underline{c}^{\mathrm{c}}$ & - & $20.5(2.3-38.8)$ & .03 & - & - \\
\hline
\end{tabular}

${ }^{\mathrm{a}} \mathrm{F} 2 \mathrm{~F}$ : face-to-face treatment.

${ }^{\mathrm{b}}$ BSCT: blended smoking cessation treatment.

${ }^{c}$ Data not shown, as for the sake of clarity only the variables of the final models are presented here. 
Table 6. Univariate predictors for adherence to face-to-face (F2F) mode and web mode in the blended treatment group.

\begin{tabular}{|c|c|c|c|c|}
\hline \multirow[t]{2}{*}{ Variable } & \multicolumn{2}{|l|}{ F2F mode } & \multicolumn{2}{|l|}{ Web mode } \\
\hline & $\begin{array}{l}\text { Regression } \\
\text { coefficient (95\% CI) }\end{array}$ & $P$ value & $\begin{array}{l}\text { Regression } \\
\text { Coefficient }(95 \% \mathrm{CI})\end{array}$ & $P$ value \\
\hline Sex & & & & .12 \\
\hline Female (reference) & $\mathrm{N} / \mathrm{A}^{\mathrm{a}}$ & & N/A & \\
\hline Male & $-\mathrm{b}$ & & $14.9(33.8$ to -3.9$)$ & \\
\hline Age & $1.9(0.2-3.6)$ & .03 & $0.8(0.1-1.5)$ & .03 \\
\hline Housing situation & & .02 & & - \\
\hline Children (reference) & N/A & & - & \\
\hline No children & $49.7(6.8-92.7)$ & & - & \\
\hline Main income & & - & & .07 \\
\hline Wage or own company (reference) & - & & N/A & \\
\hline Income support & - & & $-17.2(-36.0$ to -1.5$)$ & \\
\hline Main day activity & & - & & .02 \\
\hline Paid work (reference) & - & & Ref & \\
\hline Other & - & & $-21.7(-40.3$ to -3.1$)$ & \\
\hline Internet skills & $-3.0(-6.8-0.8)$ & .12 & - & - \\
\hline Reason to start treatment & & - & & .09 \\
\hline Extrinsic (reference) & - & & N/A & \\
\hline Intrinsic & - & & $-16.9(-36.4-2.5)$ & \\
\hline Nicotine dependency & - & - & $-6.1(-10.5$ to -1.8$)$ & .01 \\
\hline Negative attitude towards quitting & - & - & $3.8(0.9-6.7)$ & .01 \\
\hline Self-efficacy & - & - & $1.4(-0.3-3.2)$ & .12 \\
\hline Social modeling & - & - & $-3.1(-6.6-0.4)$ & .08 \\
\hline Health complaints (MAPHSS ${ }^{\mathrm{c}}$ ) & - & - & $-2.4(-3.8$ to -0.9$)$ & .001 \\
\hline Smoking-related complaints & - & - & $-1.0(-2.0-0.1)$ & .06 \\
\hline Health and smoking-related complaints & - & - & $-0.9(-1.6$ to -0.3$)$ & .01 \\
\hline Anxiety & - & - & $-2.2(-3.7$ to -0.6$)$ & .01 \\
\hline Stress & - & - & $-1.4(-2.6$ to -0.2$)$ & .03 \\
\hline $\operatorname{DASS}^{\mathrm{d}}$ & - & - & $-0.6(-1.1$ to -0.1$)$ & .02 \\
\hline EQ-5D-3L ${ }^{\mathrm{e}}$ & - & - & $28.9(-8.1-65.8)$ & .13 \\
\hline
\end{tabular}

${ }^{\mathrm{a}} \mathrm{N} / \mathrm{A}$ : not applicable.

${ }^{\mathrm{b}}$ Data not shown, since for the sake of clarity only variables that were included in the multivariate regression at $P<.15$ are shown in the table. ${ }^{c}$ MAPHASS: Maudsley Addiction Profile Health Symptoms Scale.

${ }^{\mathrm{d}}$ DASS: Sum of Depression, Anxiety, and Stress scores.

${ }^{\mathrm{e}}$ EQ-5D-3L: societal-based quantification of health status. 
Table 7. Multivariate model of patient characteristics predicting adherence to face-to-face (F2F) and web mode in the blended treatment group.

\begin{tabular}{|c|c|c|c|c|}
\hline \multirow[t]{2}{*}{ Variable } & \multicolumn{2}{|l|}{ F2F mode } & \multicolumn{2}{|l|}{ Web mode } \\
\hline & Regression coefficient $(95 \% \mathrm{CI})$ & $P$ value & Regression coefficient $(95 \% \mathrm{CI})$ & $P$ value \\
\hline Housing situation & & .02 & & $-^{\mathrm{a}}$ \\
\hline Children (reference) & $\mathrm{N} / \mathrm{A}^{\mathrm{b}}$ & & - & \\
\hline No children & $49.7(6.8-92.7)$ & & - & \\
\hline Reason to start treatment & & - & & .02 \\
\hline Extrinsic (reference) & - & & N/A & \\
\hline Intrinsic & - & & $-21.5(-39.8$ to -3.3$)$ & \\
\hline Negative attitude toward quitting & - & - & $3.6(0.9-6.4)$ & .01 \\
\hline Health complaints (MAPHSS ${ }^{\mathrm{c}}$ ) & - & - & $-2.4(-3.8$ to -1.0$)$ & .001 \\
\hline
\end{tabular}

${ }^{\mathrm{a}}$ Data not shown, as for the sake of clarity only the variables of the final models are presented here.

${ }^{\mathrm{b}} \mathrm{N} / \mathrm{A}$ : not applicable.

${ }^{c}$ MAPHSS: Maudsley Addiction Profile Health Symptoms Scale.

\section{Discussion}

\section{Principal Findings}

Since the emergence of web-based health promotion counseling a few decades ago, blended treatments have recently been introduced. The aim of the present study was to directly compare adherence to a blended treatment with a face-to-face treatment for smoking cessation with similar content.

Based on the treatment times documented in the hospital administration, we found comparable adherence levels for the blended and face-to-face treatments. However, within the blended treatment, we found that patients spent twice as much time in face-to-face mode ( $152 \%$ of the intended treatment time) than in web mode ( $75 \%$ of the intended treatment time), suggesting a tendency to substitute web sessions by additional face-to-face sessions.

Older age was the only characteristic consistently found to predict higher adherence to both the face-to-face and blended treatments. For the face-to-face group, we found that both older age and perceived social support for smoking cessation predicted higher adherence. Age is known as a relevant demographic characteristic for predicting adherence [34,35], but more social support to quit smoking has not yet been indicated as an independent predictor of adherence.

Within the blended treatment, no consistent predictor of adherence was found for its two modes of delivery. Higher adherence to the face-to-face mode was predicted by the housing situation (ie, living without children), whereas adherence to the web mode was predicted by an extrinsic motivation to quit, a less negative attitude toward quitting, and less health complaints. Although these models contained statistically significant predictive patient characteristics, the predicted proportion of variability in adherence was small, ranging from $3.4 \%$ to $16.4 \%$. Thus, it seems immature to interpret these findings in an attempt to understand the mechanisms in adherence to blended smoking cessation treatment, and it is difficult to find a meaningful pattern in these predictors. To explain this low model fit, two aspects can be considered. First, this could indicate that the predictors examined in this study, namely only the patient characteristics, are not comprehensive. For example, it seems likely that provider-related variables and health care system factors such as treatment costs, failure to recall a receipt of a prescription, and access to free nicotine replacement therapy [6] also play a role. As no data on these factors were available in this study, this could not be further verified. Second, all patient-related predictors used in the current study were evaluated at the start of treatment, which means that changes in these characteristics during treatment (eg, due to negative treatment effects such as weight gain, adverse events, or withdrawal symptoms) were not considered. As an example of a positive treatment effect, in the context of smoking cessation treatment, the bidirectional relation between quitting success and adherence is known, in which early quitting success predicts higher adherence [34], while higher adherence predicts (long-term) abstinence [6-9]. Another example is the user experience that patients build during the course of treatment. Patients may experience the treatment as "useful," "easy to follow," or "stimulating" and adhere to the treatment accordingly [48,52].

In general, the finding for the blended group that treatment time not used in web mode was compensated by face-to-face mode treatment would support the expectation that in blended treatment, the strengths of one mode of delivery will compensate for the weaknesses of the other [4,18-23]. This expectation is also supported based on our recently published qualitative study on user experience with this blended smoking cessation treatment $[48,52]$, in which we also found that the strengths of the face-to-face mode can compensate for the weaknesses of the web mode. It is noteworthy that this compensation is mainly unidirectional: face-to-face mode compensates or replaces web mode and not vice versa. By exceeding the planned face-to-face treatment time by 100 minutes on average, the vast majority of patients in the blended group $(118 / 123,95.9 \%)$ spent significantly more time in face-to-face mode than in web mode. By contrast, only 5/123 (4.1\%) patients spent slightly more time (an additional 27 minutes on average) in web mode than in 
face-to-face mode. Perhaps the new and challenging web mode is not used optimally, as it can (easily) be compensated by the traditional, familiar face-to-face mode.

Although the main objective of this study was to provide a treatment time-based comparison of adherence, we would like to briefly mention two aspects that surprised us when comparing the results with one of our previous studies [10] that used a different operationalization of adherence.

First, the current study revealed rather high adherence to both the blended and face-to-face treatments. Due to differences in interventions, measurements of adherence, adjunctive support, and investigated populations, adherence rates for smoking cessation treatment vary widely between different studies (5\%-96\%) [6]. This makes it difficult to compare adherence rates in general. Moreover, little is known about adherence rates for blended treatment. We only found one study that reported adherence rates: in a blended depression treatment, adherence to the blended treatment $(90.5 \%)$ and the face-to-face treatment $(95.1 \%)$ was comparable [53]. Our study seems to agree with this previous study, as we also found comparably high adherence to the blended (106.7\%) and face-to-face (103.3\%) treatments. Surprisingly, for the blended treatment, the findings in this study seem to contradict our findings from a previous study among participants of the blended treatment in the same sample [10], in which we reported that adherence to the blended treatment seemed rather low. These apparent contradictory results may be explained by different operationalizations of adherence and different measurement methods in the two studies. In the 2018 study, we traced treatment activities of the patients in detail (not only treatment time as used in the current study) and strived for a categorical threshold-based classification of patients as being either adherent or nonadherent. This activity-based method used in the 2018 study correlates with the time-based measurement applied in the current study, but it was more specific $[49,50]$ and therefore resulted in lower absolute adherence rates [10].

Second, in our 2018 study [10], we found that in the blended treatment, based on patients' activities, there was no significant difference in adherence to the face-to-face mode compared with the web mode. Surprisingly, in the current study, based on treatment time, the adherence levels differed significantly. Patients spent only $75.2 \%$ of the intended treatment time in the web mode, but $152.3 \%$ of the intended treatment time in the face-to-face mode. This shows that in practice it is rather a $2 / 3$ to $1 / 3$ ratio between face-to-face mode and web mode in the blended group than the planned equal ratio. This could mean, for example, that patients in face-to-face mode need more time than planned for their activities, or that additional unplanned activities take place within the treatment time. This could be an indication of therapist drift - a known weakness of face-to-face treatment [30] — and thus bring the topic of treatment fidelity into focus. From a clinical point of view, the question then arises as to whether the planned times for face-to-face mode and web mode are appropriate.

\section{Limitations and Implications for Future Work}

To the best of our knowledge, this is the first study to compare adherence and predictors of adherence in patients randomly assigned to either a blended smoking cessation treatment or a face-to-face treatment with identical active components. Moreover, this is also the first study to compare adherence and predictors of adherence to the face-to-face mode with those to the web mode of a blended smoking cessation treatment. One limitation of this study is that the measurement of adherence was based on the treatment time documented in the hospital's administrational records, as this documentation is mainly used for financial accounting and therefore does not reflect in detail the contents and the exact temporal proportions of the treatments. Even though we assume that we have a sufficiently valid measure for the comparison of adherence and for the determination of predictors, these data unfortunately do not provide deeper insight into the adherence to the treatment process in detail. For example, the specific treatment activities carried out in different time frames remain unclear. In addition, the time data for the sessions were standard values and not exactly determined as treatment time per session. Individual sessions may therefore have been shorter or longer than evaluated. The absolute time values should therefore be interpreted with caution. Furthermore, in view of the differences between the results of this study and those of the 2018 study [10], in which different operationalizations of adherence were applied (time-based vs activity-based), the methodological question also arises as to which operationalization best reflects adherence. From our previous studies [49,50], we know that activity-based measurement has better predictive validity, which makes it seem more adequate when adherence is considered a determinant of efficacy (dose-response relationship). In this study, however, we used a time-based measurement because it requires less financial and time effort, the possibility of analyzing a larger sample size allowed us to expect more accurate statistics, and because we wanted to gain more experience with its application in clinical practice. The differences found in adherence between the 2018 study and the present study bring forth an interesting issue that deserves more attention and should be targeted in future studies, such as by addressing the research questions of this study using activity-based measurement to analyze the entire sample.

Another limitation is the low variability of adherence explained by our prediction models. The question arises as to whether the chosen predictors and their measurement are sufficient. Future research should further investigate which additional predictors (eg, provider behavior, health system factors, or other patient characteristics) should be included and how these can be measured, not only at the beginning but also over the course of treatment, so that they fit optimally to the research question.

Another point of interest should be the difference in predictors and levels of adherence to the two modes of delivery in the blended treatment. The characteristics associated with adherence are quite different (adherence to the face-to-face mode of the blended treatment was mostly associated with demographic characteristics, whereas adherence to the web mode of the blended treatment was mainly associated with smoking-related and health-related characteristics). Future research should examine the causation of these differences. For example, it is possible that web-mode treatment is better suited for patients with less health complaints because they rely less on a hospital setting and the direct contact to a health care professional such 
as the smoking cessation counselor. Alternatively, web-mode treatment might be better suited for externally motivated patients because they already arrive at the treatment with a default desire to do what they are told and are therefore more likely to stick to the web mode.

Furthermore, the differences in the blended treatment adherence levels are noteworthy. In web mode, the adherence level was in the expected range, whereas there was overadherence found for the face-to-face mode. This could be related to the fact that the treatment basically starts with a rather long face-to-face session and therefore results in a type of face-to-face default mode. Therefore, it is possible that the result would have been different if the treatment had started in web mode. The overadherence raises another question as to which level of adherence is optimal to reach the treatment goals; that is, is higher adherence ( $152 \%$ adherence to face-to-face mode) better than lower adherence (ie, $75 \%$ adherence to web mode)?

\section{Conclusion}

This study represents one of the first attempts to thoroughly compare adherence and predictors of adherence of a blended smoking cessation treatment to a face-to-face treatment. Our results showed that the levels of adherence to both treatments were comparable. However, within the blended treatment, we found that adherence to face-to-face mode was significantly higher than that of web mode, although the intended total treatment time for the blended treatment was fairly broadly adhered to. This supports the idea that in blended treatment, one mode of delivery can compensate for the weaknesses of the other. Older age was found to be a common predictor of adherence to the treatments. However, within the blended treatment, adherence to each mode was predicted by different characteristics: adherence to the face-to-face mode was associated with demographic characteristics only, whereas adherence to the web mode of the blended treatment was also associated with several smoking-related and health-related characteristics. This may indicate that these characteristics should be taken into account when designing a blended treatment. However, the finding that only a small amount of the variance could be determined by the characteristics examined in this study suggests that provider-related health system factors and time-varying patient characteristics can also play an important role and should be explored in future research.

\section{Acknowledgments}

This research is funded by the Technology, Health \& Care Research Group at Saxion University of Applied Sciences and the Centre for eHealth and Well-being Research at University of Twente. We would like to thank the directors and the personnel of Medisch Spectrum Twente Hospital and Tactus Addiction Treatment, and the patients of the outpatient smoking cessation clinic of Medisch Spectrum Twente Hospital.

\section{Authors' Contributions}

LS, MEP, MGJBK, and MGP identified the study questions, and designed the study and its measuring instruments. LS is the principal investigator and wrote the first draft of this manuscript. LS, MEP, MGJBK, MGP, RS, and SBA edited the manuscript. LS, MEP, MGJBK, MGP, and RS revised the manuscript. LS wrote the final version. All authors approved the final version of this manuscript for publication.

\section{Conflicts of Interest}

None declared.

\section{Multimedia Appendix 1}

Screenshots of the web sessions of the blended smoking cessation treatment. [PDF File (Adobe PDF File), 1447 KB-Multimedia Appendix 1]

\section{Multimedia Appendix 2}

CONSORT-eHEALTH checklist (V 1.6.1). [PDF File (Adobe PDF File), $250 \mathrm{~KB}-$ Multimedia Appendix 2]

\section{References}

1. Tobacco Fact sheet. World Health Organization. 2017. URL: http://www.who.int/mediacentre/factsheets/fs339/en/ [accessed 2017-08-24]

2. Oh H, Rizo C, Enkin M, Jadad A. What is eHealth (3): a systematic review of published definitions. J Med Internet Res 2005 Feb 24;7(1):e1 [FREE Full text] [doi: 10.2196/jmir.7.1.e1] [Medline: 15829471]

3. Alvarez RC. The promise of e-Health - a Canadian perspective. eHealth Int 2002 Sep 17;1(1):4 [FREE Full text] [doi: 10.1186/1476-3591-1-4] [Medline: 12459044]

4. Erbe D, Eichert H, Riper H, Ebert DD. Blending Face-to-Face and Internet-Based Interventions for the Treatment of Mental Disorders in Adults: Systematic Review. J Med Internet Res 2017 Sep 15;19(9):e306 [FREE Full text] [doi: 10.2196/jmir.6588] [Medline: 28916506] 
5. Kemmeren LL, van Schaik DJF, Riper H, Kleiboer AM, Bosmans JE, Smit JH. Effectiveness of blended depression treatment for adults in specialised mental healthcare: study protocol for a randomised controlled trial. BMC Psychiatry 2016 Apr 21;16:113 [FREE Full text] [doi: 10.1186/s12888-016-0818-5] [Medline: 27102812]

6. Sabaté E, editor. Adherence to long-term therapies: evidence for action. Geneva: World Health Organization; 2003.

7. Alterman AI, Gariti P, Cook TG, Cnaan A. Nicodermal patch adherence and its correlates. Drug Alcohol Depend 1999 Jan 07;53(2):159-165. [doi: 10.1016/s0376-8716(98)00124-0] [Medline: 10080041]

8. Westman EC, Behm FM, Simel DL, Rose JE. Smoking behavior on the first day of a quit attempt predicts long-term abstinence. Arch Intern Med 1997 Feb 10;157(3):335-340. [Medline: 9040302]

9. Fish LJ, Peterson BL, Namenek Brouwer RJ, Lyna P, Oncken CA, Swamy GK, et al. Adherence to nicotine replacement therapy among pregnant smokers. Nicotine Tob Res 2009 May;11(5):514-518 [FREE Full text] [doi: 10.1093/ntr/ntp032] [Medline: 19351783 ]

10. Siemer L, Brusse-Keizer MG, Postel MG, Ben Allouch S, Patrinopoulos Bougioukas A, Sanderman R, et al. Blended Smoking Cessation Treatment: Exploring Measurement, Levels, and Predictors of Adherence. J Med Internet Res 2018 Aug 01;20(8):e246 [FREE Full text] [doi: 10.2196/jmir.9969] [Medline: 30068503]

11. Bosworth H, editor. Improving Patient Treatment Adherence A Clinician's Guide. Heidelberg: Springer; 2010.

12. Stead LF, Koilpillai P, Fanshawe TR, Lancaster T. Combined pharmacotherapy and behavioural interventions for smoking cessation. Cochrane Database Syst Rev 2016 Mar 24;3:CD008286. [doi: 10.1002/14651858.CD008286.pub3] [Medline: 27009521]

13. Lancaster T, Stead LF. Individual behavioural counselling for smoking cessation. Cochrane Database Syst Rev 2017 Mar 31;3:CD001292 [FREE Full text] [doi: 10.1002/14651858.CD001292.pub3] [Medline: 28361496]

14. Civljak M, Stead LF, Hartmann-Boyce J, Sheikh A, Car J. Internet-based interventions for smoking cessation. Cochrane Database Syst Rev 2013 Jul 10(7):CD007078. [doi: 10.1002/14651858.CD007078.pub4] [Medline: 23839868]

15. Taylor GMJ, Dalili MN, Semwal M, Civljak M, Sheikh A, Car J. Internet-based interventions for smoking cessation. Cochrane Database Syst Rev 2017 Sep 04;9:CD007078 [FREE Full text] [doi: 10.1002/14651858.CD007078.pub5] [Medline: 28869775]

16. Whittaker R, Borland R, Bullen C, Lin RB, McRobbie H, Rodgers A. Mobile phone-based interventions for smoking cessation. Cochrane Database Syst Rev 2009 Oct 07(4):CD006611. [doi: 10.1002/14651858.CD006611.pub2] [Medline: 19821377]

17. Whittaker R, McRobbie H, Bullen C, Rodgers A, Gu Y. Mobile phone-based interventions for smoking cessation. Cochrane Database Syst Rev 2016 Apr 10;4:CD006611 [FREE Full text] [doi: 10.1002/14651858.CD006611.pub4] [Medline: 27060875]

18. Wentzel J, van der Vaart R, Bohlmeijer ET, van Gemert-Pijnen JEWC. Mixing Online and Face-to-Face Therapy: How to Benefit From Blended Care in Mental Health Care. JMIR Ment Health 2016 Feb 09;3(1):e9 [FREE Full text] [doi: 10.2196/mental.4534] [Medline: 26860537]

19. Barak A, Hen L, Boniel-Nissim M, Shapira N. A Comprehensive Review and a Meta-Analysis of the Effectiveness of Internet-Based Psychotherapeutic Interventions. J Technol Hum Serv 2008 Jul 03;26(2-4):109-160. [doi: 10.1080/15228830802094429]

20. Kemmeren LL, van Schaik DJF, Riper H, Kleiboer AM, Bosmans JE, Smit JH. Effectiveness of blended depression treatment for adults in specialised mental healthcare: study protocol for a randomised controlled trial. BMC Psychiatry 2016 Apr 21;16:113 [FREE Full text] [doi: 10.1186/s12888-016-0818-5] [Medline: 27102812]

21. Postel MG, Witting M, van Gemert-Pijnen JEWC. Blended behandeling in de geestelijke gezondheidszorg (Blended treatment in mental health care). Dth: kwartaaltijdschrift voor directieve therapie en hypnose 2013;33(3):210-221.

22. Siemer L, Pieterse ME, Brusse-Keizer MGJ, Postel MG, Ben Allouch S, Sanderman R. Study protocol for a non-inferiority trial of a blended smoking cessation treatment versus face-to-face treatment (LiveSmokefree-Study). BMC Public Health 2016 Nov 24;16(1):1187 [FREE Full text] [doi: 10.1186/s12889-016-3851-x] [Medline: 27881108]

23. van der Vaart R, Witting M, Riper H, Kooistra L, Bohlmeijer ET, van Gemert-Pijnen LJEWC. Blending online therapy into regular face-to-face therapy for depression: content, ratio and preconditions according to patients and therapists using a Delphi study. BMC Psychiatry 2014 Dec 14;14:355 [FREE Full text] [doi: 10.1186/s12888-014-0355-z] [Medline: 25496393]

24. Schuster R, Leitner I, Carlbring P, Laireiter A. Exploring blended group interventions for depression: Randomised controlled feasibility study of a blended computer- and multimedia-supported psychoeducational group intervention for adults with depressive symptoms. Internet Interv 2017 Jun;8:63-71 [FREE Full text] [doi: 10.1016/j.invent.2017.04.001] [Medline: 30135830]

25. Kooistra LC, Wiersma JE, Ruwaard J, van Oppen P, Smit F, Lokkerbol J, et al. Blended vs. face-to-face cognitive behavioural treatment for major depression in specialized mental health care: study protocol of a randomized controlled cost-effectiveness trial. BMC Psychiatry 2014 Oct 18;14:290 [FREE Full text] [doi: 10.1186/s12888-014-0290-z] [Medline: 25326035]

26. Bruinsma A, Kampman M, Exterkate CC, Hendriks GJ. [An exploratory study of 'blended' cognitive behavioural therapy (CBT) for patients with a panic disorder: results and patients' experiences]. Tijdschr Psychiatr 2016;58(5):361-370 [FREE Full text] [Medline: 27213635] 
27. Kleiboer A, Smit J, Bosmans J, Ruwaard J, Andersson G, Topooco N, et al. European COMPARative Effectiveness research on blended Depression treatment versus treatment-as-usual (E-COMPARED): study protocol for a randomized controlled, non-inferiority trial in eight European countries. Trials 2016 Aug 03;17(1):387 [FREE Full text] [doi: 10.1186/s13063-016-1511-1] [Medline: 27488181]

28. Massoudi B, Blanker MH, van Valen E, Wouters H, Bockting CLH, Burger H. Blended care vs. usual care in the treatment of depressive symptoms and disorders in general practice [BLENDING]: study protocol of a non-inferiority randomized trial. BMC Psychiatry 2017 Jun 13;17(1):218 [FREE Full text] [doi: 10.1186/s12888-017-1376-1] [Medline: 28610561]

29. Harrington KF, McDougal JA, Pisu M, Zhang B, Sadasivam RS, Houston TK, CHART Collaborative Group. Web-based smoking cessation intervention that transitions from inpatient to outpatient: study protocol for a randomized controlled trial. Trials 2012 Aug 01;13:123 [FREE Full text] [doi: 10.1186/1745-6215-13-123] [Medline: 22852802]

30. Månsson KNT, Skagius Ruiz E, Gervind E, Dahlin M, Andersson G. Development and initial evaluation of an Internet-based support system for face-to-face cognitive behavior therapy: a proof of concept study. J Med Internet Res 2013 Dec 10;15(12):e280 [FREE Full text] [doi: 10.2196/jmir.3031] [Medline: 24326065]

31. Kay-Lambkin F, Baker A, Lewin T, Carr V. Acceptability of a clinician-assisted computerized psychological intervention for comorbid mental health and substance use problems: treatment adherence data from a randomized controlled trial. J Med Internet Res 2011 Jan 27;13(1):e11 [FREE Full text] [doi: 10.2196/jmir.1522] [Medline: 21273184]

32. Hantsoo L, Epperson CN, Thase ME, Kim DR. Antepartum depression: treatment with computer-assisted cognitive-behavioral therapy. Am J Psychiatry 2013 Aug;170(8):929-930 [FREE Full text] [doi: 10.1176/appi.ajp.2013.13020254] [Medline: 23903340]

33. Wilhelmsen M, Lillevoll K, Risør MB, Høifødt R, Johansen ML, Waterloo K, et al. Motivation to persist with internet-based cognitive behavioural treatment using blended care: a qualitative study. BMC Psychiatry 2013 Nov 07;13:296 [FREE Full text] [doi: 10.1186/1471-244X-13-296] [Medline: 24199672]

34. Hays JT, Leischow SJ, Lawrence D, Lee TC. Adherence to treatment for tobacco dependence: association with smoking abstinence and predictors of adherence. Nicotine Tob Res 2010 Jun;12(6):574-581. [doi: 10.1093/ntr/ntq047] [Medline: 20457644]

35. Ben Taleb Z, Ward KD, Asfar T, Bahelah R, Maziak W. Predictors of adherence to pharmacological and behavioral treatment in a cessation trial among smokers in Aleppo, Syria. Drug Alcohol Depend 2015 Aug 01;153:167-172 [FREE Full text] [doi: 10.1016/j.drugalcdep.2015.05.038] [Medline: 26077603]

36. Mathew M, Morrow JR, Frierson GM, Bain TM. Assessing digital literacy in web-based physical activity surveillance: the WIN study. Am J Health Promot 2011;26(2):90-95. [doi: 10.4278/ajhp.091001-QUAN-320] [Medline: 22040389]

37. Gerhards SAH, Abma TA, Arntz A, de Graaf LE, Evers SMAA, Huibers MJH, et al. Improving adherence and effectiveness of computerised cognitive behavioural therapy without support for depression: a qualitative study on patient experiences. J Affect Disord 2011 Mar;129(1-3):117-125. [doi: 10.1016/j.jad.2010.09.012] [Medline: 20889214]

38. Asfar T, Al Ali R, Rastam S, Maziak W, Ward KD. Behavioral cessation treatment of waterpipe smoking: The first pilot randomized controlled trial. Addict Behav 2014 Jun;39(6):1066-1074 [FREE Full text] [doi: 10.1016/j.addbeh.2014.02.012] [Medline: 24629480]

39. Heffner JL, Lewis DF, Winhusen TM. Preliminary evidence that adherence to counseling mediates the effects of pretreatment self-efficacy and motivation on outcome of a cessation attempt in smokers with ADHD. Nicotine Tob Res 2013 Feb;15(2):393-400 [FREE Full text] [doi: 10.1093/ntr/nts135] [Medline: 22949577]

40. Busnello RG, Melchior R, Faccin C, Vettori D, Petter J, Moreira LB, et al. Characteristics associated with the dropout of hypertensive patients followed up in an outpatient referral clinic. Arq Bras Cardiol 2001 May;76(5):349-354 [FREE Full text] [doi: 10.1590/s0066-782x2001000500001] [Medline: 11359183 ]

41. Saghaei M, Saghaei S. Implementation of an open-source customizable minimization program for allocation of patients to parallel groups in clinical trials. JBiSE 2011;04(11):734-739. [doi: 10.4236/jbise.2011.411090]

42. van Deursen AJAM, Courtois C, van Dijk JAGM. Internet Skills, Sources of Support, and Benefiting From Internet Use. Int J Hum Comput Interact 2014 Mar 07;30(4):278-290. [doi: 10.1080/10447318.2013.858458]

43. Mudde AN, Willemsen NC, Kremers SPJ, de Vries H. Meetinstrumenten voor onderzoek naar roken en stoppen met roken. In: Den Haagtivoro. The Hague: Stivoro; 2000:9071263096-9789071263095.

44. Mudde AN, Willemsen MC, Kremers S, de Vries H. Meetinstrumenten voor onderzoek naar roken en stoppen met roken [Measuring instruments for smoking and smoking cessation research] 2nd edition. The Hague: Stivoro; 2006.

45. Richtlijn behandeling van tabaksverslaving, herziening 2009 Guidelines for treating tobacco addiction. Utrecht: Centraal BegeleidingsOrgaan; 2009. URL: https://www.nhg.org/sites/default/files/content/nhg_org/uploads/ tabaksverslaving-herziening.pdf [accessed 2020-05-02]

46. Zorgmodule Stoppen met Roken. Den Haag: Partnership Stop met Roken,; 2009. URL: https://www.nhg.org/themas/ publicaties/nhg-zorgmodule-leefstijl-roken-volledige-tekst [accessed 2020-05-02]

47. Michie S, Richardson M, Johnston M, Abraham C, Francis J, Hardeman W, et al. The behavior change technique taxonomy (v1) of 93 hierarchically clustered techniques: building an international consensus for the reporting of behavior change interventions. Ann Behav Med 2013 Aug;46(1):81-95. [doi: 10.1007/s12160-013-9486-6] [Medline: 23512568] 
48. Siemer L, Ben Allouch S, Pieterse M, Brusse-Keizer M, Sanderman R, Postel M. Patients' User Experience of a Blended Face-to-Face and Web-Based Smoking Cessation Treatment: Qualitative Study. JMIR Form Res 2020 Jun 03;4(6):e14550 [FREE Full text] [doi: 10.2196/14550] [Medline: $\underline{\text { 32343245] }}$

49. Siemer L, Brusse-Keizer M, Postel M, Ben AS, Patrinopoulos A, Sanderman R. How do we measure adherence to a blended smoking cessation treatment? 2019 Presented at: Supporting Health by Technology IX; 2019; Groningen. [doi: 10.1183/13993003.congress-2018.pa1227]

50. Siemer L, Brusse-Keizer M, Postel M, Ben AS, Patrinopoulos A, Sanderman R. Adherentie aan een blended stoppen-met-roken interventie: hoe meten we adherentie, hoe adherent zijn patienten en wat voorspelt adherentie? 2019 Presented at: NNvt Congres; 2019; Utrecht. [doi: 10.2196/preprints.9969]

51. Patrinopoulos BA. Adherence to blended smoking cessation treatment. Enschede: University of Twente; 2017.

52. Siemer L, Ben AS, Pieterse M, Brusse-Keizer M, Sanderman R, Postel M. Blended face-to-face and web-based smoking cessation treatment (BSCT): a description of patients? user experience (UX). Eur Resp J 2019;54(Suppl 63):PA1690. [doi: 10.2196/preprints.14550]

53. Wright JH, Wright AS, Albano AM, Basco MR, Goldsmith LJ, Raffield T, et al. Computer-assisted cognitive therapy for depression: maintaining efficacy while reducing therapist time. Am J Psychiatry 2005 Jun;162(6):1158-1164. [doi: 10.1176/appi.ajp.162.6.1158] [Medline: 15930065]

\author{
Abbreviations \\ DASS: Depression Anxiety Stress Scale \\ eHealth: electronic health \\ MAPHSS: Maudsley Addiction Profile Health Symptoms Scale \\ RCT: randomized controlled trial
}

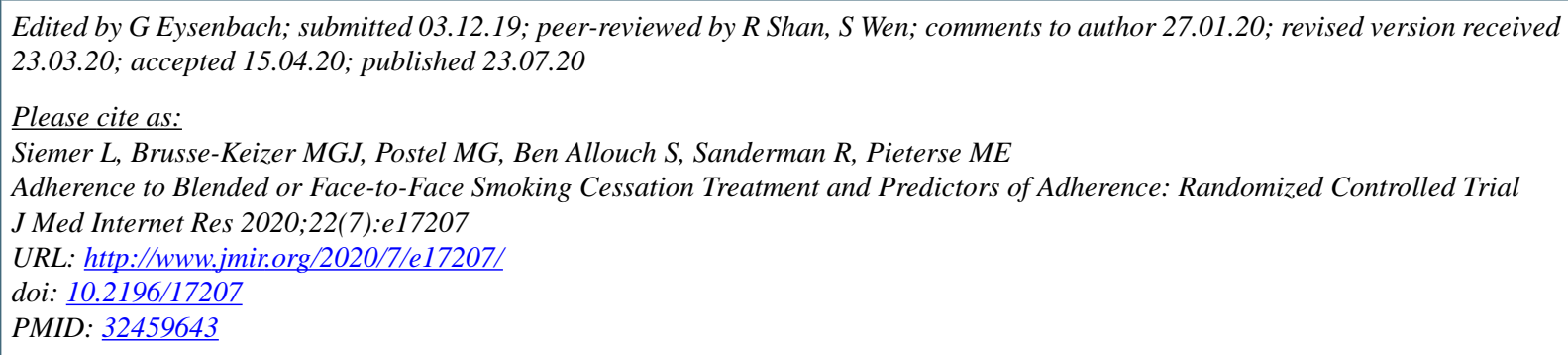

CLutz Siemer, Marjolein G J Brusse-Keizer, Marloes G Postel, Somaya Ben Allouch, Robbert Sanderman, Marcel E Pieterse. Originally published in the Journal of Medical Internet Research (http://www.jmir.org), 23.07.2020. This is an open-access article distributed under the terms of the Creative Commons Attribution License (https://creativecommons.org/licenses/by/4.0/), which permits unrestricted use, distribution, and reproduction in any medium, provided the original work, first published in the Journal of Medical Internet Research, is properly cited. The complete bibliographic information, a link to the original publication on http://www.jmir.org/, as well as this copyright and license information must be included. 